\title{
Sputum eosinophilia is more closely associated with airway responsiveness to bradykinin than methacholine in asthma
}

\author{
R. Polosa*, L. Renaud*, R. Cacciola*, G. Prosperini*, N. Crimi*, R. Djukanovic
}

Sputum eosinophilia is more closely associated with airway responsiveness to bradykinin than methacholine in asthma. R. Polosa, L. Renaud, R. Cacciola, G. Prosperini, N. Crimi, R. Djukanovic. @ERS Journals Ltd 1998.

ABSTRACT: Hyperresponsiveness of the airways to various spasmogenic stimuli is a characteristic feature of bronchial asthma. However, the association between the different stimuli to which asthmatic airways are hyperresponsive and airways inflammation is not completely understood.

We have investigated the relationship between airway inflammation and airway hyperresponsiveness in asthma, as assessed by bronchoprovocation tests to methacholine and bradykinin, two well defined bronchoconstrictor agonists. Sputum induction by hypertonic saline and methacholine and bradykinin challenges were performed in 14 nonsmoking subjects with mild-to-moderate asthma.

Airway responsiveness to either agonist did not correlate with sputum neutrophils, lymphocytes, and macrophages. Whilst the absolute number of eosinophilia failed to be significantly related to methacholine responsiveness $(\mathrm{r}=-\mathbf{0 . 4 7} ; \mathrm{p}=0.09)$, it correlated markedly and significantly with provocative concentration of methacholine causing a $20 \%$ fall in forced expiratory volume in one second $(r=0.72 ; p<0.01)$. When expressed as \% of total cell counts, sputum eosinophils correlated with both types of responsiveness $(r=-0.56 ; p=0.04$ and $r=-0.76, p<0.001$, respectively). Although the concentration of eosinophil cationic protein (ECP) in the sputum correlated with the absolute numbers of eosinophils $(r=0.62 ; p<0.02)$, no correlation was found between ECP levels and the airway responsiveness to any of the agonists tested.

In subjects with mild-to-moderate asthma, airway responsiveness to bradykinin is more strongly associated with the magnitude of eosinophilic inflammation in the airways than methacholine. This finding underlines the selectivity of diverse agonists in assessing airway hyperresponsiveness and cellular inflammation in asthma.

Eur Respir J 1998; 12: 551-556.
*Istituto Malattie Apparato Respiratorio, University of Catania, Catania, Italy. versity Medicine, Southampton General Hospital, Southampton UK

Correspondence: R. Polosa

University Medicine

D Level, Centre Block

Southampton General Hospital

Southampton SO16 6YD

UK

Fax: 441703701771

Keywords: Bradykinin

bronchial hyperreactivity

eosinophils

methacholine

sputum

Received: October 51997

Accepted after revision May 101998
The role of inflammation in asthma is widely appreciated, and airway eosinophilic inflammation is considered to be one of the most important features of the pathology of this disease [1]. The importance of airway eosinophilia as a major marker of disease activity has been documented in a number of studies [2-5]. The eosinophil is believed to be one of the key cells responsible for the development of many of the features of asthma, including damage and shedding of the respiratory epithelium, allergen-induced late asthmatic reactions, and airway hyperresponsiveness [6].

The existence of a possible correlation between the magnitude of airway eosinophilic inflammation and the degree of airway hyperresponsiveness to methacholine or histamine has been controversial, with some studies reporting a correlation between the magnitude of eosinophilic inflammation and airway responsiveness to methacholine or histamine in bronchial biopsies [7] and in bronchoalveolar lavage (BAL) fluid $[8,9]$ and others failing to establish an association [10-12].

Besides methacholine and histamine, asthmatic subjects have also exaggerated airway responses to bradykinin [13, 14], which is a pro-inflammatory nonapeptide produced de novo in body fluids and tissues during inflammatory conditions including bronchial asthma [15]. Methacholineand histamine-induced bronchoconstriction are likely to be due, primarily, to a "direct" effect of these agonists on specific receptors on the airway smooth muscle. In contrast, the underlying mechanism of bronchoconstriction for bradykinin is mainly "indirect", involving neural reflexes [15].

In order to further improve the understanding of bradykinin effects in asthma we have sought evidence for an association between airway inflammation and responsiveness to bradykinin. We have therefore investigated the relationship between infiltrate of inflammatory cells by means of sputum induction and airway hyperresponsiveness to bradykinin and methacholine in asthmatic subjects.

\section{Methods}

\section{Subjects}

Fourteen nonsmoking asthmatic subjects ( 9 female, 5 male) with a mean ( \pm SEM) age of 27.6 \pm 2.1 yrs who met the American Thoracic Society's diagnostic criteria of asthma 
Table 1. - Demographic details of subjects studied

\begin{tabular}{|c|c|c|c|c|c|c|}
\hline $\begin{array}{l}\text { Subject } \\
\text { No. }\end{array}$ & Sex & $\begin{array}{l}\text { Age } \\
\text { yrs }\end{array}$ & $\begin{array}{c}\text { Baseline FEV1 } \\
\% \text { predicted }\end{array}$ & $\begin{array}{l}\text { PC20 bradykinin } \\
\mathrm{mg} \cdot \mathrm{mL}^{-1}\end{array}$ & $\begin{array}{c}\text { PC20 methacholine } \\
\mathrm{mg} \cdot \mathrm{mL}^{-1}\end{array}$ & Regular medication \\
\hline 1 & $\mathrm{M}$ & 31 & 90 & 0.05 & 0.60 & $\mathrm{~S}$ \\
\hline 2 & $\mathrm{~F}$ & 23 & 99 & 1.69 & 4.52 & \\
\hline 3 & $\mathrm{~F}$ & 22 & 84 & 0.65 & 1.09 & $\mathrm{~S}, \mathrm{BDP}(1,000 \mu \mathrm{g})$ \\
\hline 4 & $\mathrm{~F}$ & 26 & 86 & 1.50 & 1.97 & $\mathrm{~S}, \mathrm{BDP}(2,000 \mu \mathrm{g})$ \\
\hline 5 & $\mathrm{M}$ & 23 & 91 & 0.06 & 1.09 & $\mathrm{~S}$ \\
\hline 6 & $\mathrm{~F}$ & 43 & 80 & 3.88 & 8.11 & \\
\hline 7 & M & 19 & 99 & 0.75 & 10.50 & \\
\hline 8 & $\mathrm{M}$ & 38 & 85 & 0.12 & 3.33 & $S$ \\
\hline 9 & $\mathrm{~F}$ & 25 & 87 & 0.08 & 1.46 & $\mathrm{~S}$ \\
\hline 10 & $\mathrm{~F}$ & 36 & 97 & 0.20 & 1.34 & $\mathrm{~S}$ \\
\hline 11 & $\mathrm{~F}$ & 37 & 106 & 3.08 & 8.98 & \\
\hline 12 & $\mathrm{M}$ & 22 & 83 & 0.06 & 2.72 & $\mathrm{~S}$ \\
\hline 13 & $\mathrm{~F}$ & 18 & 88 & 4.75 & 4.25 & $\mathrm{~S}, \operatorname{BDP}(1,000 \mu \mathrm{g})$ \\
\hline 14 & $\mathrm{~F}$ & 23 & 77 & 0.53 & 0.25 & S \\
\hline Mean & & 27.6 & 89.4 & $0.45^{*}$ & $2.25 *$ & \\
\hline SEM & & \pm 2.1 & \pm 2.2 & $(0.05-4.75)$ & $(0.25-10.50)$ & \\
\hline
\end{tabular}

*: geometric mean (range); FEV1: forced expiratory volume in one second; PC20: provocation concentration causing a $20 \%$ fall in FEV1; S: salbutamol p.r.n.; BDP: beclomethasone dipropionate b.i.d.

[16] participated in the study (table 1). All were previously shown to have exaggerated responses to both inhaled methacholine and bradykinin. All the subjects studied were atopic, as defined by positive skin prick tests $(>3 \mathrm{~mm}$ wheal response) to one or more of seven common airborne allergens (Dermatophagoides pteronyssinus, D. farinae, mixed grass pollen, mixed tree pollen, mixed weed pollen, cat fur, and dog hair). Their baseline forced expiratory volume in one second ( $\mathrm{FEV} 1$ ) was $>75 \%$ predicted, and none had ever received oral corticosteroids or theophylline. All were controlled on inhaled $\beta$-agonists as required, with the exception of those subjects who also took regular inhaled corticosteroids. Inhaled bronchodilators were withheld for at least $12 \mathrm{~h}$ prior to each visit, but subjects were allowed to continue their inhaled corticosteroids as usual. None of the subjects studied had experienced a respiratory tract infection or exacerbation of their asthma for at least 6 weeks before or during the study. The study was approved by the local hospitals ethical committee and written informed consent was given by all the subjects.

\section{Study design}

The study consisted of three study days outside the pollen season which were carried out at the same time of the day $(09.00 \mathrm{~h})$. On the first day, subjects attended the laboratory to undergo a methacholine challenge to determine the provocative concentration of methacholine causing a $20 \%$ fall in FEV1 (PC20) from baseline. Two days later sputum induction by hypertonic saline was performed according to a recently validated protocol [17]. The expectorated sputum was immediately collected and processed. On the final visit (5-7 days later), subjects attended the laboratory and had bradykinin challenge, to determine their PC20 bradykinin values.

\section{Bronchial provocation}

Methacholine chloride and bradykinin acetate salt (Sigma, St Louis, MO, USA) were dissolved in phosphate- buffered saline (PBS) ( $\mathrm{pH}$ 7.4) to produce increasing doubling concentrations ranging from $0.03-16 \mathrm{mg} \cdot \mathrm{mL}^{-1}$ for methacholine and from $0.015-4 \mathrm{mg} \cdot \mathrm{mL}^{-1}$ for bradykinin and immediately used for bronchial challenge. The solutions were administered as aerosols generated from a starting volume of $3 \mathrm{~mL}$ in a disposable Inspiron Minineb (C.R. Bard International, Sunderland, UK) driven by compressed air at $8 \mathrm{~L} \cdot \mathrm{min}^{-1}$. Patients inhaled the aerosolized solution in five breaths from functional residual capacity to near total lung capacity via a mouthpiece. Patients were trained to reach total lung capacity in $3 \mathrm{~s}$.

FEV1 was measured using a dry wedge spirometer (Vitalograph, Buckinghamshire, UK). After 15 min rest, three consecutive baseline measurements of FEV1 were made at intervals of 2 min and the best result recorded. Challenges were preceded by inhalation of PBS and only subjects in whom this caused $<10 \%$ decreases from baseline FEV 1 were studied. Immediately after challenge with diluent, increasing doubling concentrations of methacholine or bradykinin were administered. FEV1 was measured at 1 and 3 min after administration of each concentration of agonist. The challenges were discontinued when FEV1 had fallen by $>20 \%$ of the postdiluent value. The bronchial responses to the inhaled agonists were expressed as the $\mathrm{PC}_{20}$, which was derived by linear interpolation from the concentration-response curve constructed by plotting the percentage change in FEV1 from the post-diluent value against the cumulative concentration of agonist administered on a logarithmic scale.

\section{Sputum induction}

Sputum induction was performed according to our published method [17]. Briefly, after stopping $\beta_{2}$-agonists for at least $12 \mathrm{~h}$, subjects inhaled hypertonic saline (4.5\%) aerosolized by an ultrasonic nebulizer (UltraNeb 99; DeVilbiss, Feltham, Middlesex, UK) with output set at $3 \mathrm{~mL} \cdot \mathrm{min}^{-1}$. The subjects wore a nose clip and quietly inhaled aerosol for up to four consecutive 5-min periods. After each inhalation, the subjects rinsed their mouth with water and dried 
it with tissue paper to minimize contamination with saliva. They then expectorated the sputum into a Petri dish, which was immediately placed onto ice until processing. FEV1 was then measured between procedures for safety reasons; if the fall in FEV1 was $>20 \%$ of baseline, the challenge was discontinued.

\section{Sputum processing and analysis}

Whole sputum was transferred into $50 \mathrm{~mL}$ polypropylene tubes (Becton Dickinson, Abingdon, UK), weighed, and an equal weight of $0.01 \mathrm{M}$ dithioerythritol (DTE; Fluka, Gillingham, Dorset, UK) solution added to solubilize the mucus. Specimens were then vortexed for $10 \mathrm{~s}$, rocked for $30 \mathrm{~min}$ at room temperature, and vortexed again for $10 \mathrm{~s}$. They were then filtered through a $70 \mathrm{~mm}$ strainer (Becton Dickinson) and the collected fluid centrifuged at $400 \times \mathrm{g}$ for $10 \mathrm{~min}$ at $4^{\circ} \mathrm{C}$. The supernatants were removed and stored at $-20^{\circ} \mathrm{C}$. The cell pellets were resuspended in $1 \mathrm{~mL}$ PBS without $\mathrm{Ca}^{2+}$ and $\mathrm{Mg}^{2+}$ and viable cells counted in a haemocytometer. Only samples in which squamous cells comprised $<30 \%$ of total cells were considered satisfactory for analysis. Differential counting was carried out on cytospins stained with May-Grunwald-Giemsa and 600 cells (excluding squamous cells) counted. Slides were coded and examined by one investigator. Eosinophil counts were expressed as a percentage of the number of total cells and as absolute numbers. Eosinophil cationic protein (ECP) levels were measured in duplicate by a commercially available fluorometric enzyme immunoassay (FEIA; Pharmacia, Uppsala, Sweden) with a sensitivity of $2 \mathrm{mg} \cdot \mathrm{L}^{-1}$.

\section{Data analyses}

Baseline values of FEV1 were compared between and within study days by two-factor analysis of variance (ANOVA) followed by Neuman-Keuls test where appropriate.
PC20 methacholine and bradykinin values were logarithmically transformed to normalize their distribution and expressed as geometric mean (range). All other variables which were not normally distributed were expressed as median (range). The relationship between methacholine $\mathrm{PC}_{20}$ and bradykinin PC20 was studied by least squares linear regression after logarithmically transforming the PC20 values. All the data for cells and ECP in the sputum samples had a non-normal distribution. Thus, for correlation analyses of the data that included sputum variables and airway responses to bradykinin and methacholine, the Spearman's rank-order test was used. Values of $\mathrm{p}<0.05$ were considered to indicate statistical significance.

\section{Results}

There was no significant difference in baseline values of FEV 1 between any of the three study days, with mean ( \pm SEM) values ranging from $2.95 \pm 0.20$ to $3.10 \pm 0.23 \mathrm{~L}$. The geometric mean (range) PC20 values for methacho-line and for bradykinin were $2.25 \mathrm{mg} \cdot \mathrm{mL}^{-1}(0.25-10.50$ $\left.\mathrm{mg} \cdot \mathrm{mL}^{-1}\right)$ and $0.45 \mathrm{mg} \cdot \mathrm{mL}^{-1}\left(0.05-4.75 \mathrm{mg} \cdot \mathrm{mL}^{-1}\right)$, respectively (table 1). A weak but significant correlation was observed between methacholine $\mathrm{PC} 20$ and bradykinin PC20 $(\mathrm{r}=0.54, \mathrm{p}=0.046)$.

Sputum induction was well tolerated by all subjects studied. Inhalation of hypertonic saline caused a mean fall in FEV 1 of $0.24 \pm 0.08 \mathrm{~L}$. None of the subjects studied experienced a fall in FEV $1>20 \%$ after sputum induction.

The median (range) inflammatory cell count in sputum was $2.3 \%(0.6-22.7 \%)$ for eosinophils, $21.3 \%(7.0-35.8 \%)$ for neutrophils, $4.0 \%(0.9-11.3 \%)$ for lymphocytes and $69.0 \%$ (51.0-91.0\%) for macrophages (table 2).

The median (range) ECP concentration measured in the sputum supernatant was $29.1(5.4-563.7) \mathrm{ng} \cdot \mathrm{mL}^{-1}$. The concentration of ECP measured in the fluid phase correlated strongly and significantly with the absolute numbers of sputum eosinophils $(\mathrm{r}=0.62 ; \mathrm{p}<0.02)$.

There was a tendency towards a correlation between methacholine PC20 values and the absolute count of eosinophils in sputum, which failed to reach statistical significance

Table 2. - Total and percentage cell counts in the sputum of the subjects studied

\begin{tabular}{|c|c|c|c|c|c|c|c|}
\hline $\begin{array}{l}\text { Subject } \\
\text { No. }\end{array}$ & $\begin{array}{l}\text { Total cell counts* } \\
\times 10^{3} \cdot \mathrm{g} \mathrm{sputum}^{-1}\end{array}$ & $\begin{array}{c}\text { Squamous cells } \\
\%\end{array}$ & $\begin{array}{c}\text { Macrophages } \\
\%\end{array}$ & $\begin{array}{c}\text { Lymphocytes } \\
\%\end{array}$ & $\begin{array}{c}\text { Neutrophils } \\
\%\end{array}$ & $\begin{array}{c}\text { Eosinophils } \\
\%\end{array}$ & $\begin{array}{c}\mathrm{ECP} \\
\mathrm{ng} \cdot \mathrm{mL}^{-1}\end{array}$ \\
\hline 1 & 1,800 & 28 & 68.5 & 4.0 & 21.5 & 6.0 & 40.8 \\
\hline 2 & 2,300 & 16 & 69.0 & 3.2 & 26.0 & 1.8 & 134.6 \\
\hline 3 & 320 & 12 & 75.1 & 4.3 & 19.1 & 1.5 & 10.0 \\
\hline 4 & 350 & 22 & 77.0 & 1.0 & 21.0 & 1.0 & 5.4 \\
\hline 5 & 547 & 30 & 51.0 & 11.3 & 15.0 & 22.7 & 445.5 \\
\hline 6 & 375 & 8 & 70.2 & 5.1 & 24.1 & 0.6 & 52.8 \\
\hline 7 & 537 & 25 & 64.0 & 8.0 & 25.3 & 2.7 & 5.5 \\
\hline 8 & 1,005 & 24 & 52.0 & 6.0 & 24.0 & 18.0 & 563.7 \\
\hline 9 & 517 & 10 & 68.9 & 3.9 & 8.0 & 19.2 & 71.1 \\
\hline 10 & 427 & 27 & 79.0 & 2.5 & 12.5 & 6.0 & 21.7 \\
\hline 11 & 397 & 25 & 67.0 & 9.1 & 23.0 & 0.9 & 36.0 \\
\hline 12 & 637 & 11 & 85.3 & 3.1 & 10.1 & 1.5 & 8.2 \\
\hline 13 & 1,155 & 10 & 91.0 & 1.3 & 7.0 & 0.7 & 13.3 \\
\hline 14 & 772 & 18 & 53.7 & 0.9 & 35.8 & 9.6 & 22.2 \\
\hline Mean & 795.6 & 19.0 & 69.41 & 4.55 & 19.46 & 6.59 & 102.2 \\
\hline SEM & 158.5 & 2.1 & 3.17 & 0.83 & 2.16 & 2.07 & 46.9 \\
\hline Median & 542.0 & 20 & 68.95 & 3.95 & 21.25 & 2.25 & 29.1 \\
\hline
\end{tabular}

*: excluding squamous cells; ECP: eosinophil cationic protein. 

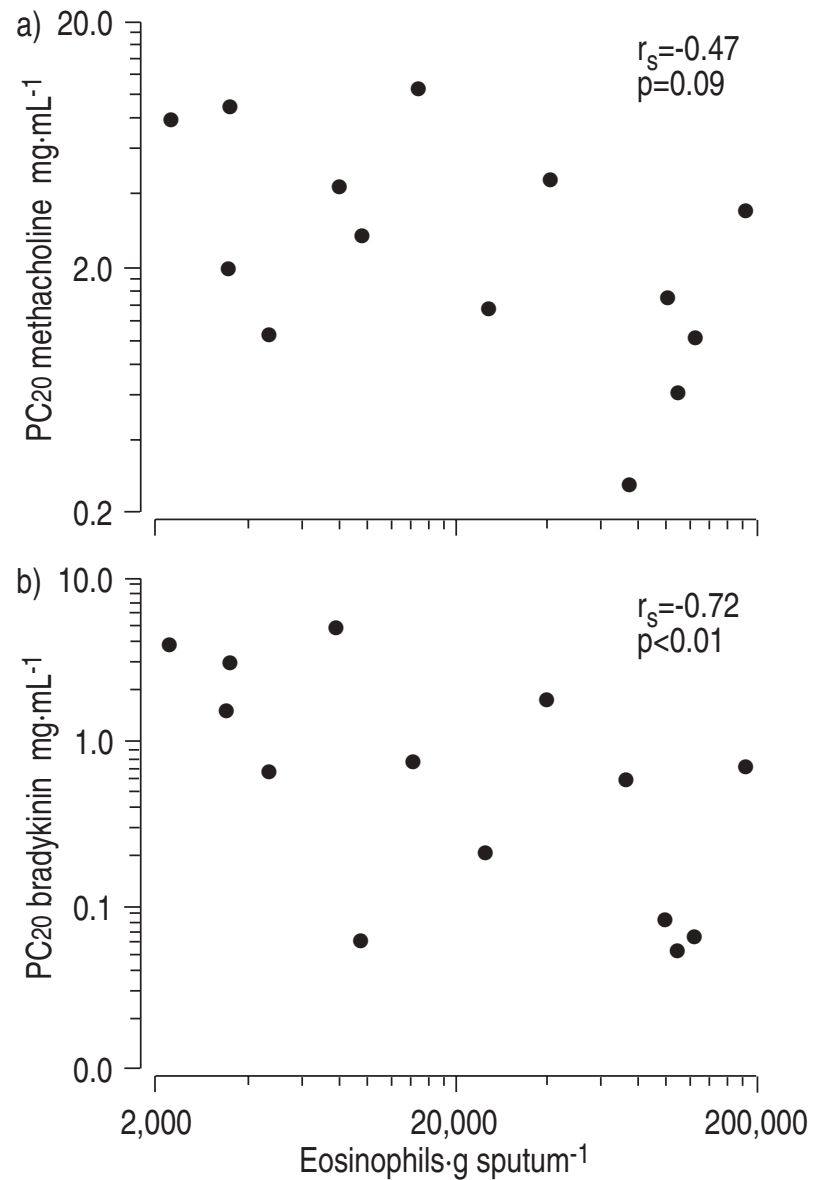

Fig. 1. - Correlation between the number of eosinophils in the sputum and the provocative concentration causing a $20 \%$ fall in forced expiratory volume in one second (PC20) of methacholine (a) and bradykinin (b) in asthmatic subjects $(n=14)$. The strength of the association was analysed by Spearman's rank-order test.

$\left(r_{s}=-0.47, p=0.09\right.$, fig. 1a). Indeed, when the sputum eosinophilia was expressed as a percentage of total cell counts, a weak but significant association with the PC20 values for methacholine was found $(\mathrm{r}=-0.56, \mathrm{p}=0.04)$.

However, there was a marked and significant negative correlation between bradykinin PC20 values and sputum eosinophils, both in terms of absolute $(\mathrm{r}=-0.72, \mathrm{p}<0.01$, fig. 1b) and of percentage counts $\left(r_{\mathrm{s}}=-0.76, \mathrm{p}<0.001\right)$.

No significant correlation was found between the concentration of ECP in sputum and the airway responsiveness to either of the agonists tested.

Furthermore, we found no significant correlation between the $\mathrm{PC}_{20}$ values for methacholine or bradykinin and either the percentage or the absolute count of lymphocytes, neutrophils, and macrophages.

\section{Discussion}

It has long been appreciated that airway hyperresponsiveness is not a nonspecific phenomenon and that responses to individual agonists, such as histamine, methacholine, exercise and bradykinin, are not necessarily closely associated [18]. This is likely to reflect different components of asthma pathogenesis which can be identified by in- creased responses to a given stimulus. Consistent with this notion, in the present study we have shown a difference in the relationship between airways eosinophilia on the one hand and airway hyperresponsiveness to bradykinin and methacholine on the other.

In keeping with previous reports, airway responsiveness to both agonists did not correlate with the number (and percentage) of lymphocytes, neutrophils, and macrophages in asthmatic airways [2, 12, 19]. However, we have shown a strong negative correlation between PC20 bradykinin and sputum eosinophils, which was much stronger and significant than the association with $\mathrm{PC}_{20}$ methacholine. The presence of ECP in association with an increased number of eosinophils in the sputum reflects that activation and degranulation of eosinophils occurs in the airway mucosa of these subjects. Whilst our findings indicate that airway responsiveness to bradykinin is related to the degree of eosinophilic infiltration, the lack of an association with ECP levels would suggest that the mechanisms involve other eosinophil mediators which, possibly together with their basic protein, contribute to the enhanced airway responses to bradykinin. However, the concentration of ECP in sputum may reflect poorly the eosinophil activation that occurs deep in the airways mucosa, thus explaining why we found no correlation between sputum ECP and airway responsiveness to bradykinin. Although we cannot exclude the possibility that this may be also due to the confounding and variable influence of saliva in induced sputum, two large studies using sputum plugs (known to contain reduced amounts of saliva) have shown a similar lack of correlation between ECP levels and airway hyperresponsiveness [20, 21].

With increasing use of induced sputum as a safe and simple means of assessing airways inflammation, a number of investigators have shown a correlation between sputum eosinophilia and airway hyperresponsiveness $[17,20$, $22]$. However, other studies have failed to relate eosinophil differential counts in sputum to airway hyperresponsiveness $[21,23]$. The reasons for such discrepancies are unclear but may be related to the diversity in clinical and functional characteristics of the subjects studied or to important differences in the study protocol or statistical conduct.

Indeed, some of these problems are well represented in the present paper. For example, we failed to show a statistically significant correlation with PC20 methacholine when the absolute count of eosinophils in sputum was used, but this relationship reached statistical significance (although weak) when the sputum eosinophilia was expressed as a percentage of total cell counts. However, our data on bradykinin are far more sound as the marked and significant negative correlation between bradykinin PC20 values and sputum eosinophils was maintained both in terms of absolute and percentage counts.

The findings of the present investigation agree with the recent study by RoIsman et al. [24], in which a significant correlation was found between airway responsiveness to bradykinin (but not methacholine) and eosinophils count in BAL and bronchial biopsies.

The stronger relationship between bradykinin airway responsiveness and airway eosinophilic inflammation cannot be explained by different conditions of airway challenge, as baseline FEV1, before methacholine and bradykinin challenges were not statistically different. Challenges were 
carried out at the same time of the day, thus ruling out a possible influence of circadian variations on airway responsiveness. Bradykinin challenge was carried out after sputum induction to avoid any inflammatory change induced by the pro-inflammatory peptide in airway mucosa. Additionally, the relatively short time interval between methacholine and bradykinin challenges allowed us to reduce the probability that the relationship between the responses to the two agonists was affected by spontaneous intraindividual variations in airway responsiveness.

The discrepancy between the two agonists for the relationship between airway responsiveness and sputum eosinophilia may reside in the difference in their mechanisms of bronchoconstrictor effect. Methacholine elicits bronchoconstriction through a direct action on the airway smooth muscle, whereas inhaled bradykinin causes bronchoconstriction mainly via "indirect" mechanisms, involving neural reflexes [15]. Further support for the differential mechanisms of action of bradykinin and methacholine is suggested by the recent demonstration that whole lung antigen challenge elicited a more marked increase in bradykinin airways responsiveness than in methacholine responsiveness and that the shifts in antigen-induced bronchial hyperresponsiveness to the two agonists followed considerably different time courses $[25,26]$. These observations of the disparate responses of bradykinin and methacholine in the setting of allergic inflammation suggest that the mechanisms by which bradykinin exerts its effects are particularly sensitive to acute inflammation of the bronchial mucosa, whereas methacholine responsiveness might predominantly be dependent on structural changes of the airways.

Several possibilities exist to explain how eosinophilic inflammation may selectively influence the response of asthmatic airways to bradykinin. Recruitment of eosinophils and release of their granular content is associated with the magnitude of airway epithelial damage and shedding in asthma [3, 27]. Eosinophils are capable of damaging the respiratory epithelium through the action of toxic products such as ECP, which are contained in their granules and secreted upon eosinophil activation [27]. In vitro, airway smooth muscle contraction to bradykinin is potentiated by loss of or damage to the airway epithelium [15, 28]. The constrictor effect of bradykinin is attenuated by the release of epithelial-derived prostaglandin E2 [29] and by its degradation by two major bronchial peptidases, neutral endopeptidase (NEP) and kininase II [15]. With damage of the epithelium and the resulting loss of these epithelial-bound peptidases, a selective increase in bradykinin airway responsiveness would be expected, because methacholine is not a substrate for these enzymes [30, 31]. Moreover, damage to the epithelium might also enhance sensory nerve stimulation to the action of bradykinin, resulting in the release of spasmogenic neuropeptides by way of an axon reflex [15].

Another potential explanation for the association between airway hyperresponsiveness to bradykinin and sputum eosinophilia is that eosinophilic inflammation may alter responsiveness to bradykinin by increasing kinin receptor expression. It has been demonstrated that interleukin (IL)1 , which is generated at sites of allergic inflammation [32], can increase the number of bradykinin receptors on human synovial cells [33]. If the expression of bradykinin receptors on target tissues is induced during allergic inflammation, this could help to explain the hyperrespon- siveness to bradykinin seen in patients with high eosinophil counts in their sputum.

In asthma, the responsiveness to exogenous bradykinin is more strongly related to sputum eosinophilia than methacholine. Because the present finding underlines the selectivity of bradykinin in assessing airway hyperresponsiveness in relation to the degree of eosinophilic inflammation, in the future it would be of interest to examine the clinical usefulness of bradykinin bronchoprovocation as a marker of the severity of the inflammatory processes in asthma.

\section{References}

1. Djukanovic R, Roche WR, Wilson JW, et al. Mucosal inflammation in asthma. Am Rev Respir Dis 1990; 142: 434-457.

2. Beasley R, Roche WR, Roberts JA, Holgate ST. Cellular events in the bronchi in mild asthma and after bronchial provocation. Am Rev Respir Dis 1989; 139: 806-817.

3. Bousquet J, Chanez P, Lacoste JY, et al. Eosinophilic inflammation in asthma. N Engl J Med 1990; 323: 1033 1039.

4. Laitinen LA, Laitinen A, Haahtela T. A comparative study of the effects of an inhaled corticosteroid, budesonide and a beta2-agonist, terbutaline, on airway inflammation in newly diagnosed asthma: a randomized, double-blind, parallel-group controlled trial. J Allergy Clin Immunol 1992; 90: $32-42$.

5. Djukanovic R, Wilson JW, Britten KM, et al. Effect of an inhaled corticosteroid on airway inflammation and symptoms in asthma. Am Rev Respir Dis 1992; 145: 669-674.

6. Holgate ST, Roche W, Church MK. The role of the eosinophil in asthma. Am Rev Respir Dis 1991; 143: 566-570.

7. Bentley AM, Menz G, Storz C, et al. Identification of T lymphocytes, macrophages and activated eosinophils in the bronchial mucosa in intrinsic asthma. Relationship to symptoms and bronchial responsiveness. Am Rev Respir Dis 1992; 146: 500-506.

8. Kirby JG, Hargreave FE, Gleich GJ, O'Byrne PM. Bronchoalveolar cell profiles of asthmatic and nonasthmatic subjects. Am Rev Respir Dis 1987; 136: 379-383.

9. Ferguson AC, Wong FWM. Bronchial hyperresponsiveness in asthmatic children. Correlation with macrophages and eosinophils in broncholavage fluid. Chest 1989; 96 : 988-991.

10. Djukanovic R, Wilson JW, Britten KM, et al. Quantitation of mast cells and eosinophils in the bronchial mucosa of symptomatic atopic asthmatic and healthy control subjects using immuno-histochemistry. Am Rev Respir Dis 1990; 142: 863-871.

11. Saetta M, Di Stefano A, Maestrelli P, et al. Airway mucosal inflammation in occupational asthma induced by toluene diisocyanate. Am Rev Respir Dis 1992; 145: 160-168.

12. Adelroth E, Rosenhall L, Sten-Ake J, Linden M, Venge P. Inflammatory cells and eosinophilic activity in asthmatics investigated by bronchoalveolar lavage. The effects of antiasthmatic treatment with budesonide or terbutaline. Am Rev Respir Dis 1990; 142: 91-99.

13. Fuller RW, Dixon CMS, Cuss FMC, Barnes PJ. Bradykinin-induced bronchoconstriction in humans. Mode of action. Am Rev Respir Dis 1987; 135: 176-180.

14. Polosa R, Holgate ST. Comparative airway responses to inhaled bradykinin, kallidin and [des-Arg $\left.{ }^{9}\right]$ bradykinin in 
normal and asthmatic subjects. Am Rev Respir Dis 1990; 142: 1367-1371.

15. Polosa R. Role of the kinin-kallikrein pathway in allergic diseases. Allergy 1993; 48: 217-225.

16. American Thoracic Society. Standards for the diagnosis and care of patients with chronic obstructive pulmonary disease (COPD) and asthma. Am Rev Respir Dis 1987; 136: 225-243.

17. Renaud L, Shute J, Biagi S, et al. Cell infiltration, ICAM1 expression, and eosinophil chemotactic activity in asthmatic sputum. Am J Respir Crit Care Med 1997; 155: 466-472.

18. Sterk PJ. Bronchial hyperresponsiveness: definition and terminology. Pediatr Allergy Immunol 1996; 7 (Suppl. 9): 7-9.

19. Bradley B, Azzawi M, Jacobson M, et al. Eosinophils, Tlymphocytes, mast cells, neutrophils and macrophages in bronchial biopsy specimens from atopic subjects with asthma: comparison with biopsy specimens from atopic subjects without asthma and normal control subjects and relationship to bronchial hyperresponsiveness. J Allergy Clin Immunol 1991; 88: 661-674.

20. Ronchi MC, Piragino C, Rosi E, et al. Do sputum eosinophils and ECP relate to the severity of asthma. Eur Respir J 1997; 10: 1809-1813.

21. Spanevello A, Migliori GB, Sharara A, et al. Induced sputum to assess airway inflammation: a study of reproducibility. Clin Exp Allergy 1997; 27: 1138-1144.

22. Pizzichini E, Pizzichini MMM, Efthimiadis A, et al. Indices of airway inflammation in induced sputum: reproducibility and validity of cell and fluid-phase measurements. Am J Respir Crit Care Med 1996; 154: 308-317.

23. Iredale MJ, Wanklin SAR, Phillips IP, Krausz T, Ind PW. Non-invasive assessment of bronchial inflammation in asthma: no correlation between eosinophilia of induced sputum and bronchial responsiveness to inhaled hypertonic saline. Clin Exp Allergy 1994; 24: 940-945.
24. Roisman GL, Lacronique JG, Desmazes-Dufeu N, Carrè C, Le Cae A, Dusser DJ. Airway responsiveness to bradykinin is related to eosinophilic inflammation in asthma. Am J Respir Crit Care Med 1996; 153: 381-390.

25. Djukanovic R, Polosa R, Holgate ST. The effect of bronchial allergen challenge on methacholine and bradykinin airway responsiveness. Eur Respir J 1991; 4: Suppl. 14, 340s.

26. Berman AR, Togias AG, Skloot G, Proud D. Allergeninduced hyperresponsiveness to bradykinin is more pronounced than that to methacholine. J Appl Physiol 1995; 78: 1844-1852.

27. Gleich GJ. The eosinophil and bronchial asthma: current understanding. J Allergy Clin Immunol 1990; 85: 422436.

28. Frossard N, Stretton CD, Barnes PJ. Modulation of bradykinin responses in airway smooth muscle by epithelial enzymes. Agents Action 1990; 31: 204-209.

29. Bramley AM, Samhoun MN, Piper PJ. The role of epithelium in modulating the responses of guinea pig trachea induced by bradykinin in vitro. Br J Pharmacol 1990; 99: 762-766.

30. Dusser DJ, Nadel JA, Sekizawa K, Graf PD, Borson DB. Neutral endopeptidase and angiotensin converting enzyme inhibitors potentiate kinin induced contraction of ferret trachea. J Pharmacol Exp Ther 1988; 244: 531-536.

31. Crimi N, Polosa R, Pulvirenti G, et al. The effect of an inhaled neutral endopeptidase inhibitor, phosphoramidon, on baseline airway caliber and bronchial responsiveness to bradykinin in asthma. Thorax 1995; 50: 505-510.

32. Bochner BS, Charlesworth EN, Lichtenstein LM, et al. Interleukin-1 is released at sites of human cutaneous allergic reactions. J Allergy Clin Immunol 1990; 86: 830-839.

33. Bathon JM, Manning DC, Goldman DW, Towns MC, Proud D. Characterization of kinin receptors on human synovial cells and upregulation of receptor number by interleukin-1. J Pharmacol Exp Ther 1992; 260: 384-392. 